\author{
Rolf van Hulten · K. Bart Teeuw · Albert Bakker \\ Hubert G. Leufkens
}

\title{
Initial 3-month usage characteristics predict long-term use of benzodiazepines: an 8-year follow-up
}

Received: 26 November 2002/ Accepted: 15 November 2002/ Published online: 7 February 2003

(C) Springer-Verlag 2003

\begin{abstract}
Objective: The aim of the study was to identify initial usage predictors for prolonged benzodiazepine use. Methods: An 8-year pharmacy data-based study (1983-1992) was carried out on a retrospective cohort of 425 initial benzodiazepine users. The setting was the only pharmacy in a community of 13,500 people. Results: Among the 425 initial users, 36\% had a single initial exposure year, $50 \%$ had two to seven exposure years, and $14 \%$ had benzodiazepine use during all 8 years of follow-up. Prolonged use over more years was associated with an initial high number of prescriptions, elderly patients and initial use of hypnotics. Two patterns of irregular prolonged use were investigated: increase in use was associated with a shorter length of the first usage period and switching to another benodiazepine during the first 90 days; relapses of use were associated with a shorter length of first usage period and initial use of an anxiolytic. Gender and initial dosage were not associated with prolonged use at all. Conclusion: During the first 90 days after initiation of benzodiazepine use, a number of determinants of prolonged benzodiazepine use were visible. The prescribers of these drugs and the pharmacists should advise rational use not only at the start but also at the moment of the first repeat prescription in order to prevent needless prolonged use and dependence.
\end{abstract}

Keywords Benzodiazepines - Long-term use · General population

R. van Hulten $(\bowtie) \cdot$ K.B. Teeuw · A. Bakker · H.G. Leufkens Department of Pharmacoepidemiology and Pharmacotherapy, Utrecht Institute for Pharmaceutical Sciences (UIPS),

Utrecht University, P.O. Box 80.082, 3508TB,

Utrecht, The Netherlands

E-mail: r.p.vanhulten@pharm.uu.nl

Tel.: + 31-30-2537324

Fax: + 31-30-2539166

\section{Introduction}

Benzodiazepines are one of the most widely prescribed groups of drugs, despite a decrease in use suggested in recent surveys of benzodiazepine utilisation in the UK, the USA and Germany [1, 2, 3, 4]. Shortly after their introduction, side effects of benzodiazepines such as dependence and difficulty to discontinue began to arouse concern. Therefore, the reduction of benzodiazepine prescribing is an important issue with respect to the risk of dependence and the seemingly needless long-term use $[5,6]$. Ideally, benzodiazepines are prescribed for a limited period of time. For example, in the Netherlands, hypnotics are recommended for 10-14 days of continuous use [7]. Benzodiazepines are mainly prescribed by general practitioners $[8,9,10]$. Decision making about rational use and reduction in needless long-term use, therefore, has to be done in the primary care setting. The prescriber and those pharmacists who monitor patients should have knowledge of the risk characteristics for prolonged benzodiazepine use. Mant et al. found that the main predictors of benzodiazepine prescribing were three clinical factors (namely presenting problems of anxiety and insomnia, and the number of health problems) together with patient age [11]. Simon et al. analysed the initial prescription and the likelihood of continued use over 6 months [10]. In the latter study, patient age, use of high-potency drugs (such as lorazepam, alprazolam and clonazepam) and a larger number of pills in the initial prescription were associated with increased duration of use. Isacson found in a 1997 study that age, prescriptions by other than the general practitioner and frequent or daily use in the first year were associated with a long-term use of 13 years [12].

In this study, we investigated the characteristics of initial prescription and usage patterns during the first 90 days after inclusion as predictors of prolonged benzodiazepine use. The objective was to identify these pharmacy-related predictors in an 8-year retrospective cohort study of initial users in a Dutch community. It is 
conceivable that the prescriber and the pharmacist will give more attention to a new benzodiazepine user during the short period after the initial prescription. Appropriate risk management of benzodiazepine use during this first period could prevent needless prolonged use and dependence.

\section{Methods and materials}

\section{Study population and data collection}

Pharmacy data were collected in a distinct area in the northwest of the Netherlands. At the start of the cohort in 1984, approximately 11,500 people lived in the central community and 1000 lived in the rural surroundings. Six general practitioners were responsible for primary care. The prescriptions for the total population were dispensed from a single pharmacy. During the study period, there were no interventions to enhance appropriate benzodiazepine use.

Data on prescriptions of benzodiazepines dispensed during the years 1983-1992 were retrieved from automated pharmacy records. In the Netherlands, benzodiazepines can only be obtained on prescription. The pharmacy records cannot provide indications for use from the prescriber. However, indications for benzodiazepine use are limited (e.g. insomnia, anxiety). The pharmacy records provide accurate and complete study material. The maximum usage length of benzodiazepine prescriptions dispensed in this pharmacy was 30 days. All prescriptions were accompanied by instructions for dose and length of use. A drug was defined as a benzodiazepine if coded according to the Anatomical Therapeutic and Chemical (ATC) classification system as: N05BA (tranquillisers or anxiolytics), N05CD (hypnotics/sedatives) or N05CF and N05CG (benzodiazepine-related hypnotics/sedatives) [13].

We selected a retrospective cohort of initial users of benzodiazepines in 1984. Initial users were defined as adults (18 years and older) who received a benzodiazepine prescription in the pharmacy in the year 1984 without any benzodiazepine prescription in a period of 365 days before the inclusion date. The definition of initial use was according to other studies in the field, in particular those by Isacson [9]. The follow-up of 8 years started at each individual inclusion date in 1984. Of these 8 years, a year was defined an 'exposure year' if there had been any benzodiazepine use. Persons were not eligible if they moved outside the catchment area or died during the study period 1983-1992. Population census data of the study period was obtained from the local authorities. Because of reliability of pharmacy data, the assumption has been made that prescribed use approximates actual benzodiazepine use.

\section{Outcome variable}

Prolonged benzodiazepine use was defined as use during more than one (the first) exposure year. In order to investigate determinants of different patterns of prolonged use, we analysed two main characteristics of prolonged benzodiazepine use: (1) one plain characteristic, e.g. the total number of exposure years, and (2) two more dynamic characteristics-the change in use over time and the number of relapses of use.

The sum of the cumulative exposure years was categorised in 1 , $2-7$, and 8 years. The first category represents those subjects with exposure during the first year only, the second category represents those subjects with prolonged use able to stop for at least 1 year during follow-up, and the last category represents those subjects with use during all 8 years of follow-up.

Change in use (or more precisely change in number of usage days) during the last 7 years of follow-up of each individual benzodiazepine user was calculated using linear regression, analysing the change in the number of days of use per exposure year, including the year after termination. From the resulting regression coefficient and intercept, the percentage change per exposure year was calculated. Change in prolonged use was categorised as 'decrease' in use, 'stable' use and 'increase' in use. Relapses of use during the last 7 years of follow-up were defined as a restart of benzodiazepine use after stopping for more than 90 days. Relapses during prolonged use were defined in contrast to continued prolonged use. Both change in use and number of relapses of use were calculated for all subjects using more than only a single exposure year.

\section{Independent variables}

Three categories of predictor variables were defined: patient characteristics (age and gender), characteristics of the initial prescription, and usage characteristics of the first 90 days after initiation. Characteristics of the initial prescription were categorised by ATC codes and the defined daily dose (DDD) measurement [14]. DDD equivalents were calculated by dividing the prescribed daily dose by the DDD of the individual benzodiazepine. The following pharmacological categories by ATC code were defined (see Appendix): hypnotics versus anxiolytics; short elimination half-life $(<20 \mathrm{~h})$ versus long half-life drugs $(>19 \mathrm{~h})$ including half-life of metabolites; drugs with a fast $\mathrm{t}_{\max }(<2$ hours) versus drugs with a slow $t_{\max }(>2 \mathrm{~h})$; and drugs with a 5-aryl halogenated group versus drugs without such a group, since these latter drugs are possibly higher potency benzodiazepines $[15,16]$.

We took the first 90 days after inclusion as the initial period of use. Usage characteristics of this period comprised the number of prescriptions, number of episodes of use, length of the initial episode of use, double medication (simultaneous use of two different benzodiazepines) and switching between different benzodiazepines. Double medication and switching were assessed on the fifth level of ATC classification ('subgroup of chemical substance') [13]. In this context, episodes were defined as periods of use without stopping for more than 30 days.

We used chunk-wise backward variable selection in logistic regression modelling to determine predictors for the outcome definitions of benzodiazepine use [17]. Database management was performed using the SAS statistical program (SAS Institute Inc., Cary, NC, USA). Logistic regression was conducted using the SPSS package for Windows, Release 6.1.3, (SPSS Inc., Chicago, IL, USA).

\section{Results}

In 1984 , a total of 1345 persons in the study population received a benzodiazepine prescription. Of this group, $556(41.3 \%)$ persons were initial users. Relative to current users, initial users were more often male [male: 200 initial $(36.0 \%)$ versus 226 current (28.6\%)] and predominantly younger [mean age initial 50 years (SD 18) versus current 61 years (SD 16)]. In the sample of initial users, 425 persons were eligible, since 68 persons died and 63 moved during follow-up. Of these latter groups, 31 of $68(45.6 \%)$ died and 28 of $63(44.4 \%)$ moved within 2 years after inclusion. The mean age of the included users was 48 years (SD 17 years, median 46 years; 25 th percentile 35 years; and 75 th percentile 62 years)

Characteristics of the 425 eligible users are presented in Table 1. Initially, $29.9 \%$ of the users were prescribed a hypnotic. Subsequently, in the last exposure year of follow-up, one in two of the remaining users was exposed to a hypnotic. Initially, $53.8 \%$ were prescribed 
Table 1 Characteristics of initial benzodiazepine (BZD) users $(n=425)$

\begin{tabular}{|c|c|c|c|}
\hline \multicolumn{2}{|l|}{ Characteristics } & \multirow{2}{*}{$\frac{n}{288}$} & \multirow{2}{*}{$\frac{\%}{67.8}$} \\
\hline Gender & Female & & \\
\hline \multirow[t]{3}{*}{ Age (years) } & $<45$ & 200 & 47.1 \\
\hline & $45-64$ & 142 & 33.4 \\
\hline & $>64$ & 83 & 19.5 \\
\hline \multirow[t]{8}{*}{ Initial prescribed BZD } & Oxazepam & 126 & 29.6 \\
\hline & Diazepam & 125 & 29.4 \\
\hline & Temazepam & 59 & 13.9 \\
\hline & Nitrazepam & 49 & 11.5 \\
\hline & Chlordiazepam & 22 & 5.2 \\
\hline & Lorazepam & 15 & 3.5 \\
\hline & Flunitrazepam & 10 & 2.4 \\
\hline & Flurazepam & 9 & 2.1 \\
\hline Anxiolytic & & 298 & 70.1 \\
\hline Short half-life & & 214 & 50.4 \\
\hline Fast $t_{\max }$ & & 231 & 54.4 \\
\hline 5-aryl halog & & 35 & 8.2 \\
\hline \multirow[t]{3}{*}{ Daily dose equivalent (DDD) } & $0-0.74$ & 299 & 53.8 \\
\hline & $0.75-1.24$ & 191 & 34.4 \\
\hline & $1.25+$ & 66 & 11.9 \\
\hline \multirow[t]{3}{*}{ Prescriptions 1st 90 days } & 1 & 282 & 66.4 \\
\hline & 2 & 73 & 17.2 \\
\hline & $>2$ & 70 & 16.5 \\
\hline \multirow[t]{3}{*}{ Length initial episode (days) } & $0-15$ & 142 & 33.4 \\
\hline & $16-30$ & 146 & 34.4 \\
\hline & $>30$ & 137 & 32.2 \\
\hline \multirow[t]{2}{*}{ Episodes of use (1st 90 days) } & 1 & 402 & 94.6 \\
\hline & 2 & 23 & 5.4 \\
\hline $\begin{array}{l}\text { Double medication ATC } \\
\text { code (1st } 90 \text { days) }\end{array}$ & Yes & 15 & 3.5 \\
\hline $\begin{array}{l}\text { Switching of ATC code } \\
\text { (1st } 90 \text { days) }\end{array}$ & Yes & 30 & 7.1 \\
\hline
\end{tabular}

a low dose (less than 0.75 DDD equivalent) and only $11.9 \%$ were prescribed a higher dose (1.25 DDD equivalents or more). In the first 90 days, 137 persons $(32.2 \%)$ used the medicine for more than 30 days. In the first year, 45 persons $(10.6 \%)$ used it for more than 180 days. Mean duration of the BZD prescriptions in the first period was 19.6 days (SD 11.2).

A total of $269(65 \%)$ persons terminated benzodiazepine therapy in the first year after inclusion, presenting the second year after inclusion without use. During follow-up, $114(42.4 \%)$ restarted use resulting in a cumulative use of two to seven exposure years. The total number of persons with at least one intermittent year without use during follow-up was $174(40.9 \%)$. A total of 58 persons $(13.6 \%)$ in the cohort had the full eight exposure years (Table 2).

Determinants of the number of exposure years resulting from backward logistic regression modelling are presented in Table 3. The independent variables of the analysis can be found in Table 1. Relatively more prescriptions in the first 90 days and initial benzodiazepines with a short half-life were associated with a higher risk of use for 2-7 years versus one exposure year. Age over 65 years, more than one prescription in the first 90 days and initial use of a hypnotic were associated with a higher risk of stable long-term use for eight consecutive exposure years versus one exposure year. Determinants
Table 2 Indicators of prolonged use of initial benzodiazepine users $(n=425)$

\begin{tabular}{|c|c|c|c|}
\hline Outcome prolonged use & & $n$ & $\%$ \\
\hline \multirow[t]{3}{*}{ Exposure years } & 1 & 155 & 36.5 \\
\hline & $2-7$ & 212 & 49.9 \\
\hline & 8 & 58 & 13.6 \\
\hline \multirow{3}{*}{$\begin{array}{l}\text { Change in use during } \\
\text { last } 7 \text { years follow-up }\end{array}$} & Decrease & 162 & 60.0 \\
\hline & Stable & 48 & 17.8 \\
\hline & Increase & 60 & 22.2 \\
\hline \multirow{3}{*}{$\begin{array}{l}\text { Number of relapses during } \\
\text { last } 7 \text { years follow-up }\end{array}$} & 0 & 24 & 8.9 \\
\hline & 1 & 63 & 23.3 \\
\hline & $>1$ & 183 & 67.8 \\
\hline
\end{tabular}

${ }^{a} \mathrm{n}=270$

Table 3 Determinants of the number of exposure years during 8 years of follow-up (backward logistic regression)

\begin{tabular}{|c|c|c|c|}
\hline & \multicolumn{3}{|c|}{$2-7$ versus 1 year } \\
\hline & & Odds ratio & $\begin{array}{l}95 \% \text { Confidence } \\
\text { interval }\end{array}$ \\
\hline Prescriptions & 1 & 1 & \\
\hline & $\begin{array}{l}2 \\
>2\end{array}$ & $\begin{array}{l}1.66 \\
2.66\end{array}$ & $\begin{array}{l}(0.90-3.08) \\
(1.35-5.22)\end{array}$ \\
\hline$t_{1 / 2}$ & $\begin{array}{l}\text { Long } \\
\text { Short }\end{array}$ & $\begin{array}{l}1 \\
1.57 \\
8 \text { versus } 1 \text { year } \\
\text { OR }\end{array}$ & $\begin{array}{l}(1.03-2.41) \\
(95 \% \mathrm{CI})\end{array}$ \\
\hline Age (years) & $\begin{array}{l}<45 \\
45-64 \\
>64\end{array}$ & $\begin{array}{l}1 \\
1.27 \\
5.02\end{array}$ & $\begin{array}{l}(0.53-3.06) \\
(2.09-12.04)\end{array}$ \\
\hline $\begin{array}{l}\text { Prescriptions } \\
1 \text { st } 90 \text { days }\end{array}$ & $\begin{array}{l}1 \\
2 \\
>2\end{array}$ & $\begin{array}{l}1 \\
7.74 \\
9.25\end{array}$ & $\begin{array}{l}(3.27-18.36) \\
(3.56-24.06)\end{array}$ \\
\hline $\begin{array}{l}\text { Hypnotic versus } \\
\text { Anxiolytic }\end{array}$ & & $\begin{array}{l}1 \\
0.36\end{array}$ & $(0.17-0.75)$ \\
\hline
\end{tabular}

of change in use and the number of relapses during the last 7 years of follow-up are presented in Table 4 and Table 5. No factors were significantly associated with decrease in use versus stable use. Less than 15 initial days of use in the first 90 days and switching to another benzodiazepine were associated with an increase in use during the last 7 years of follow-up. The variable 'one prescription in the first 90 days after inclusion' was significantly associated with two or more relapses versus one or no relapse in use during the last 7 years of followup.

\section{Discussion}

In this pharmacy data-based cohort study, we have examined indicators of the initial prescription and usage patterns of an initial period of use (first 90 days after inclusion) as predictors of different patterns of prolonged use. We investigated two different patterns of 
Table 4 Determinants of the change in use during the last 7 years of follow-up (backward logistic regression)

\begin{tabular}{llll}
\hline & \multicolumn{2}{l}{ Increase versus stable use } \\
\cline { 2 - 4 } & Odds ratio & $\begin{array}{l}95 \% \text { Confidence } \\
\text { interval }\end{array}$ \\
\hline $\begin{array}{l}\text { Length 1st period } \\
\text { (days) }\end{array}$ & $1-15$ & 1 & \\
\multirow{2}{*}{ Switching } & $16-30$ & 0.39 & $(0.13-1.16)$ \\
& $>30$ & 0.14 & $(0.04-0.41)$ \\
& No & 1 & $(1.18-36.12)$ \\
\hline
\end{tabular}

Table 5 Determinants of the number of relapses in use during last 7 years of follow-up (backward logistic regression)

\begin{tabular}{llll}
\hline & \multicolumn{1}{l}{$>1$ versus 1 or 0 relapse } \\
\cline { 2 - 4 } & Odds ratio & $\begin{array}{c}95 \% \text { Confidence } \\
\text { interval }\end{array}$ \\
\hline Prescriptions 1st 90 days & 1 & 1 & \\
& 2 & 0.84 & $(0.41-1.73)$ \\
& $>2$ & 0.18 & $(0.09-0.35)$ \\
Hypnotic versus & & 1 & \\
Anxiolytic & & 1.68 & $(0.95-2.95)$ \\
\hline
\end{tabular}

benzodiazepine use: (1) a plain pattern of long-term use, i.e. the total number of exposure years, associated with increased age, initial use of a hypnotic, and with two or more prescriptions in the first 90 days after inclusion, and (2) irregular patterns of prolonged use, i.e. with relapses or increasing use. The latter was associated with a relatively short initial period of use and switching to another benzodiazepine.

We used pharmacy data consisting of virtually the complete benzodiazepine exposure of the population in a Dutch community over 10 years (1983-1992) in order to realise a follow-up of 8 years. These pharmacy-based data gave us the opportunity to perform relatively accurate analyses. In the sample of initial users, corrections were made due to deaths and moves. Remarkably, a high proportion of subjects died or moved within a relatively short period of 2 years after inclusion.

We have observed a proportion of $14 \%$ of initial benzodiazepine users who continued use during all 8 years of follow-up. During a 1-year reference period, Olfson and Pincus found that about $10 \%$ of the original users took benzodiazepines in the last (12th) month [2]. Our proportion is comparable to a Swedish study by Isacson et al., who found only a slightly lower percentage $(10.6 \%)$ [9]. Isacson et al. only analysed continuing users; only those users with at least one benzodiazepine prescription per consecutive year remained in the Swedish study. We analysed cumulative exposure years, which were not always in succession. The number of persons with at least one intermittent year without use $(n=174,64 \%)$ gave a good indication of the variety in benzodiazepine usage patterns, which could hardly be described as homogeneous.

Our definition of initial use (use without a previous year of use), which has also been applied in other papers, might imply that several initial users could have been previous users in prior years before our time window. That possibly might result in some bias in our results $[10,11]$. Further research that requires a long time window should shed light on the process of stopping and restarting.

The present study provides insight into risk factors for an increase in exposure years and risk factors for change in usage days or relapses in use over time. More prescriptions in the initial 90 days were associated with more exposure years. A short initial usage period (one prescription in the initial 90 days or an initial usage period of at most 14 days), however, was associated with two subpatterns of prolonged use: more relapses during follow-up and an increase in use. We conclude that an initial small number of benzodiazepine prescriptions should not be regarded as indicative of low risk for all patterns of prolonged use. Further research should be done to provide insight in these subpatterns of prolonged use. Interestingly, the determinant for long-term use (namely "more prescriptions in the initial 90 days") as well as the determinant of increase in use (namely "switching") provide the physician and pharmacist an argument to advise the user about the risks of long-term use at the moment of the first and, possibly, the second repeat prescription in the short period of 90 days after the initial prescription. In particular, it should be easy to monitor the relatively small category of switchers during the first 90 days.

The differentiation between hypnotics and anxiolytics revealed hypnotics to be a predictor of continued use and anxiolytics to be an indicator of more relapses in use. We suggest that hypnotic users tend to continue their use as long as possible, in contrast to the users of anxiolytics, who appear more able to stop and restart use. Long-term hypnotic use, however, goes against recommendations not to use hypnotics for more than 1 week or 2 weeks continuously [7].

We also found age to be a predictor of continued use. Other reports have also identified age as a risk factor for chronic use $[12,18]$. Age, however, was not a predictor of any increase in use over time. We conclude that the elderly are at particular risk of prolonged stable use of benzodiazepines.

Survey data of benzodiazepine use have shown a consistently higher benzodiazepine use by females. We did not find gender to be a predictor of any of the characteristics of prolonged use. In other benzodiazepine utilisation studies, gender influence almost always disappeared or was mediated by other factors such as diagnosis or self-report of distress [10, 11, 19].

Two types of benzodiazepine dependence may be considered: high-dose versus therapeutic-dose dependence [20, 21, 22, 23]. High-dose dependence involves a use of high doses and a pattern of pathological use 
followed by severe withdrawal manifestations. Therapeutic-dose dependence shows a persistent therapeutic use which is longer than pharmaco-therapeutically recommended. In further research, it could be investigated whether these dependence patterns concur with the two presented patterns of long-term use of this study, i.e. increasing prolonged use and stable long-term use. The pharmacological characteristic of short half-life was associated with more exposure years during follow-up, suggesting prolonged use. Discontinuation problems of short half-life benzodiazepines have been reported previously $[24,25,26]$. The initial dose of a benzodiazepine was not associated with one of the patterns of prolonged use. After long-term therapy, the original level of the dose did not seem to be an important factor in the process of the gradual withdrawal of a benzodiazepine [27]. A higher dose is related to different features, such as more sedation and an increased risk of having accidents [28].

This report has focused on characteristics of the initial prescribed benzodiazepine and the usage characteristics of the initial 90 days. The knowledge of these characteristics is important for the decision-making process of the prescriber and the pharmacist monitoring a patient at risk. The association between the initial number of prescriptions and the number of exposure years might be explained by the severity of symptoms, which might require more benzodiazepine prescriptions, or by the emergence of dependence in the event of prolonged initial benzodiazepine use. We found an association between initial insomnia and more exposure years and an indicative association between initial anxiety and irregular prolonged use (i.e. relapses during use).

The study did lack patient-based endpoints on, for example, physical and mental health or quality of life estimates. Usage characteristics such as an initial high number of prescriptions, switching to another benzodiazepine in the first 90 days and a patient characteristic such as high age may reflect an impaired health status of the starting benzodiazepine user. Several studies have mentioned the relationship between ill health and benzodiazepine use $[29,30,31]$. A retrospective study in a group of 6921 patients in the same community found a clear association between use of benzodiazepines and chronic somatic disease [32]. Fourrier et al. reported that a poor baseline health was a determinant of a 5-year subsequent use [31]. Interestingly, another study showed that prior long-term use in a group of benzodiazepine users was not associated with an impaired health status [30]. Of the current users without impaired health, $61 \%$ had used benzodiazepines for over 5 years. Taking into account the recommendations of short-term use, it remains to be seen whether an impaired health status can be a reason for prolongation of benzodiazepine use.

This study concentrated on the identification of pharmacy-related predictors of long-term benzodiazepine use. Beyond the scope of the study is the question whether benzodiazepine prescribing in itself is appro- priate or not. As Uhlenhuth et al. stated, pharmacoepidemiological data of drug use alone do not suffice to illuminate the significance of psychotherapeutic agents and to provide a basis for medical decision making [33]. Our design and our data therefore did not provide a proper value statement on the use of benzodiazepines. However, in the case of benzodiazepine therapy, we believe that focusing on usage and drug characteristics alone is meaningful. If a benzodiazepine might be indicated, the acquired knowledge can already contribute to improved drug prescribing, drug management, and a decrease in the number of users at risk for needless prolonged use, in order to accomplish a shift from the reality of long-term prescribing towards the recommended short-term use. In conclusion, if prolonged use of benzodiazepines is not indicated, the physician and pharmacist should monitor use carefully during the first 90 days after initiation and recommend short-term use not only at the start of use but even more comprehensively at the moment of the first repeat prescription. At that time, accurate information about side effects, such as dependence and difficulty to discontinue, should and can be given.

\section{Classification of benzodiazepines in study population}

- Short $t_{1 / 2}$ : bromazepam, flunitrazepam, lorazepam, oxazepam, temazepam

- Long $t_{1 / 2}$ : chlordiazepoxide, clobazam, clorazepic acid, diazepam, flurazepam, nitrazepam, nordazepam, prazepam

- Fast $\mathrm{t}_{\max }$ : bromazepam, chlordiazepoxide, clorazepic acid, diazepam, flunitrazepam, flurazepam, temazepam

- Slow $t_{\max }$ : clobazam, lorazepam, nitrazepam, nordazepam, prazepam, oxazepam

- 5-aryl halog: flunitrazepam, flurazepam, lorazepam

- No 5-aryl halog: bromazepam, chlordiazepoxide, clobazam, clorazepic acid, diazepam, nitrazepam, nordazepam, oxazepam, prazepam, temazepam

\section{References}

1. Dunbar GC, Perera MH, Jenner FA (1994) Patterns of benzodiazepine use in Great Britain as measured by a general population survey. Br J Psychiatry 155:836-841

2. Olfson M, Pincus HA (1994) Use of benzodiazepines in the community. Arch Int Med 154:1235-1240

3. Koenig W, Ruther E, Remmers A et al (1987) Psychotropic drug utilisation patterns in a metropolitan population. Eur $\mathbf{J}$ Clin Pharmacol 32:43-51

4. Van Hulten R, Leufkens HG, Bakker A (1998) Usage patterns of benzodiazepines in a Dutch community. Pharm World Sci 20:78-82

5. Lader M (1983) Dependence on benzodiazepines. J Clin Psychiatry 44:121-127

6. Busto U, Sellers EM, Nuranjo CA et al (1986) Withdrawal reaction after long-term therapeutic use of benzodiazepines. $\mathrm{N}$ Engl J Med 315:854-859 
7. Central Medical Pharmaceutical Committee of the Council of the Dutch National Health Service (1996) Pharmaceutical compass 1996 (in Dutch). Council of the Dutch National Health Service, Amstelveen

8. Van der Waals FW, Mohrs J, Foets M (1993) Sex differences among recipients of benzodiazepines in Dutch general practice. BMJ 307:363-366

9. Isacson D, Carsjo K, Bergman U, Blackburn JL (1992) Longterm use of benzodiazepines in a Swedish community: an eightyear follow-up. J Clin Epidemiol 45:429-436

10. Simon GE, VonKorff M, Barlow W, Pabiniak C, Wagner E (1996) Predictors of chronic benzodiazepine use in a health organization sample. J Clin Epidemiol 49:1067-1073

11. Mant A, Mattick RP, De Brugh S, Donnelly N, Hall W (1995) Benzodiazepine prescribing in general practice: dispelling some myths. Fam Pract 12:37-43

12. Isacson D (1997) Long-term benzodiazepine use: factors of importance and the development of individual use patterns over time-a 13-year follow-up in a Swedish community. Soc Sci Med 44:1871-1880

13. World Health Organization (1993) Anatomical Therapeutic Chemical (ATC) classification index. World Health Organization Collaborating Centre for Drug Statistics Methodology, Oslo

14. Hekster YA, Vree TB, Goris RJ, Boerema JB (1982) The defined daily dose per 100 bed-days as a unit of comparison and a parameter for studying antimicrobial drug use in a university hospital. J Clin Hosp Pharm 7:251-260

15. Mendels J (1991) Criteria for selection of appropriate benzodiazepine hypnotics therapy. J Clin Psychiatry 1991:42-46

16. Volkerts ER, van Laar MW, Willigenburg APP, Plomp TA, Maes RAA (1992) A comparative study of on-road simulated driving performance after nocturnal treatment with lormetazepam $1 \mathrm{mg}$ and oxazepam $50 \mathrm{mg}$. Hum Psychopharmacol 7:297-309

17. Kleinbaum DG, Kupper LL, Muller KE (1988) Applied regression analysis and other multivariate methods. PWS-Kent Publishing Company, Boston

18. Mant A, Duncan-Jones P, Saltman D, Bridges-Webb C, Kehoe L, Lansbury G, Chancellor A (1988) Development of long-term use of psychotropic drugs by general practice patients. BMJ 296:251-254

19. Swartz M, Landerman R, George LK, Melville ML, Blazer D, Smith K (1991) Benzodiazepine anti-anxiety agents: prevalence and correlates of use in a southern community. Am J Publ Health 81:592-596
20. Busto U, Bendayan R, Sellers E (1989) Clinical pharmacokinetics of non-opiate abused drugs. Clin Pharmacokinet 16: $1-26$

21. Cappell H, Busto U, Kay G, Naranjo C, Sellers EMCS (1987) Drug deprivation and reinforcement by diazepam in a dependent population. Psychopharmacology 91:154-160

22. Smith DE, Wesson DR (1983) Benzodiazepine dependence syndromes. J Psychoactive Drugs 15:85-95

23. Martinez-Cano H, Vela-Bueno A, De Iceta M, Pomalima R, Martinez-Graz I, Paz Sobrino M (1996) Benzodiazepine types in high versus therapeutic dose dependence. Addiction 91:1179-1186

24. Davidson JRT (1990) Continuation treatment of panic disorder with high potency benzodiazepines. J Clin Psychiatry $51: 31-37$

25. Rickels K, Schweizer E, Case WG, Greenblatt DJ (1988) Longterm therapeutic use of benzodiazepines, effects of abrupt discontinuation. Arch Gen Psychiatry 45:444-450

26. Hallfors DD, Saxe L (1993) The dependence potential of short half-life benzodiazepines: a meta-analysis. Am J Publ Health 83:1300-1304

27. Schweizer E, Rickels K, Case WG, Greenblatt DJ (1990) Longterm therapeutic use of benzodiazepines, effects of gradual taper. Arch Gen Psychiatry 47:908-915

28. Herings RMC, Stricker BHC, De Boer A, Bakker A, Sturmans F (1995) Benzodiazepines and the risk of falling leading to femur fractures. Arch Int Med 155:1801-1807

29. Rodrigo EK, King MB, Williams P (1988) Health of long-term benzodiazepine users. BMJ 296:603-606

30. Van Hulten R, Teeuw KB, Bakker AB, Bakker A, Leufkens HG (2000) Characteristics of current benzodiazepine users as indicators of differences in physical and mental health. Pharm World Sci 22:96-101

31. Fourrier A, Letenneur L, Dartigues JF, Moore N, Begaud B (2001) Benzodiazepine use in an elderly community-dwelling population. Characteristics of users and factors associated with subsequent use. Eur J Clin Pharmacol 57:419-425

32. Van Hulten R, Heerdink ER, Bakker A, Leufkens HG (1999) Benzodiazepine pathways in the chronically ill. Pharmacoepidemiol Drug Saf 8:325-330

33. Uhlenhuth EH, Balter MB, Mellinger GD (1993) Clinical variables in pharmacoepidemiology. J Psychiatr Res 278 [Suppl 1]:89-95 